\title{
Analisis Paparan Fume Pengelasan Pada Pengelas Di Divisi Kendaraan Khusus PT. X
}

\author{
Farid Alfalaki Hamid ${ }^{1 \mathrm{a}}$, Katharina Oginawati ${ }^{2 b}$ \\ ${ }^{a}$ Politeknik Energi dan Mineral Akamigas \\ ${ }^{\mathrm{b}}$ Institut Teknologi Bandung
}

Received : 01-11-2020

Reviewed : 29-12-2020

Online Published : 31-12-2020

\begin{abstract}
Research on exposure to welding fume on welders in the Special Vehicle Division PT. X has been conducted. The use of Gas Metal Arc Welding $(G M A W)$ is getting wider in industries. Hence, health effects of weldign fume exposure had to be concerned. The objective is to determine exposure level received by welders. Non-welders works at administration department is used as control. Calibrated personal sampling pump with Mixed Cellulose Ester (MCE) Filter Used to collect air sample. Gravimetric method is used to calculate the concentraion of respirable particulate and Hazard Index (HI) is use to determine whether the welding process is danger or not. The average concentration of respirable particulate on welders is $7,913.94 \mu \mathrm{g} / \mathrm{m}^{3}$, while non-welders is $219.91 \mu \mathrm{g} / \mathrm{m}^{3}$. Hazard Index (HI) for welders is 9.45, while non-welders is 0.51. Based on that, control method is needed to reduce welding fume hazard.
\end{abstract}

Keywords: Welding Fume, GMAW, Hazard Index, Gravimetric Method

\begin{abstract}
Abstrak
Penelitian mengenai paparan fume pengelasan pada pengelas di Divisi Kendaraan Khusus PT. X telah dilakukan. Penggunaan mesin Gas Metal Arc Welding (GMAW) semakin luas di kawasan industri sehingga dampak kesehatan yang ditimbulkan fume pengelasan harus menjadi perhatian. Tujuan penelitian ini untuk mengetahui nilai paparan yang diterima pengelas. Kelompok non-pengelas merupakan pekerja di bagian administrasi digunakan sebagai pembanding. Teknik pengumpulan data menggunakan personal sampling pump terkalibrasi yang telah dipasang filter Mixed Cellulose Ester (MCE). Metode Gravimetri digunakan untuk menghitung konsentrasi partikulat terespirasi dan Indeks Bahaya (HI) digunakan untuk mengetahui bahaya dari proses pengelasan. Rata-rata konsentrasi partikulat terespirasi pada pengelas sebesar 7.913,94 $\mu \mathrm{g} / \mathrm{m}^{3}$, sedangkan pada non-pengelas $219,91 \mu \mathrm{g} / \mathrm{m}^{3}$. Indeks Bahaya (HI) kelompok pengelas sebesar 9,45 sedangkan pada kelompok non-pengelas 0,51. Untuk itu, perlu dilakukan tindakan pencegahan untuk mengurangi bahaya fume pengelasan.
\end{abstract}

Kata kunci: Fume pengelasan; GMAW; Indeks bahaya; Metode gravimetri

\section{Pendahuluan}

Pengelasan merupakan kegiatan yang telah berlangsung sejak akhir abad ke-19. Seiring dengan perkembangan industri, pengelasan merupakan suatu proses yang umum digunakan. Kita juga tak bisa mengelak bahwa pengelasan merupakan proses yang berbahaya. Pengelasan menghasilkan pijar api yang mampu membakar kulit, radiasi yang berdampak terhadap kulit dan mata (Ashby, 2002).

Salah satu bahaya yang harus diwaspadai adalah fume pengelasan. Ashby (2002) mengatakan bahwa fume merupakan partikel solid yang berasal dari welding consumable, yakni logam dasar dan pelapis yang menutupinya. Kobayashi dkk. (1983) dalam Chae et al. (2006) menambahkan fume terbentuk menjadi partikel dan kluster setelah uap logam yang dihasilkan teroksidasi, mengalami pendinginan secara cepat dan terkondensasi.

Pramudyastuti (2009) mengatakan bahwa konsentrasi fume pengelasan yang dihasilkan pada pengelasan Manual Metal Arc Welding (MMAW) berada direntang 315,6$3.735,93 \mu \mathrm{g} / \mathrm{m}^{3}$. Nilai ini mendekati TWA PEL yang ditetapkan OSHA $\left(5.000 \mu \mathrm{g} / \mathrm{m}^{3}\right)$ dan telah melewati baku mutu partikulat terespirasi yang dikeluarkan ACGIH (3.000 $\left.\mu \mathrm{g} / \mathrm{m}^{3}\right)$. Lebih jauh, Pramudyastuti juga menemukan 19 unsur logam dalam sampel fume pengelasan dan mengelompokan unsur-unsur tersebut sehingga diketahui komponen unsur yang berasal dari fume pengelasan, yakni $\mathrm{Fe}, \mathrm{Co}, \mathrm{Mn}, \mathrm{Na}$, dan K. International Agency for Research on Cancer (1990) melaporkan bahwa pada pengelasan Gas Metal Arc Welding (GMAW) dengan logam mild steel ditemukan 14 unsur logam dalam fume pengelasan dan terdapat unsur penanda berupa $\mathrm{Fe}, \mathrm{Mn}, \mathrm{Si}$, dan $\mathrm{K}$.

Untuk skala industri, mesin MMAW jarang digunakan karena menggunakan elektroda tidak kontinu. Gas Metal Arc Welding (GMAW) menjadi pilihan yang digunakan secara luas. Ini juga terjadi di PT. X yang memproduksi kendaraan fungsi khusus (rantis, tank, dan panser) di mana mesin GMAW lebih banyak digunakan karena kemudahankemudahan yang dimilikinya. Melihat bahaya yang ditimbulkan, emisi fume pengelasan perlu diwaspadai dampaknya terhadap kesehatan pengelas. Oleh karena itu, studi mengenai paparan fume pengelasan perlu dilakukan untuk memberikan pemahaman terhadap bahaya fume pengelasan.

\section{Metodologi}


Penelitian ini dilaksanakan pada bulan November hingga Maret 2012 di Departemen Produksi 1 Divisi Kendaraan Khusus PT. X (Gambar 1). Produk utama Divisi ini berupa kendaraan dengan fungsi khusus, seperti tank, kendaraan taktis, dan panser. Departemen Produksi 1 memproduksi rangka kendaraan sehingga kegiatan di departemen ini didominasi pemotongan, grinding, dan pengelasan.

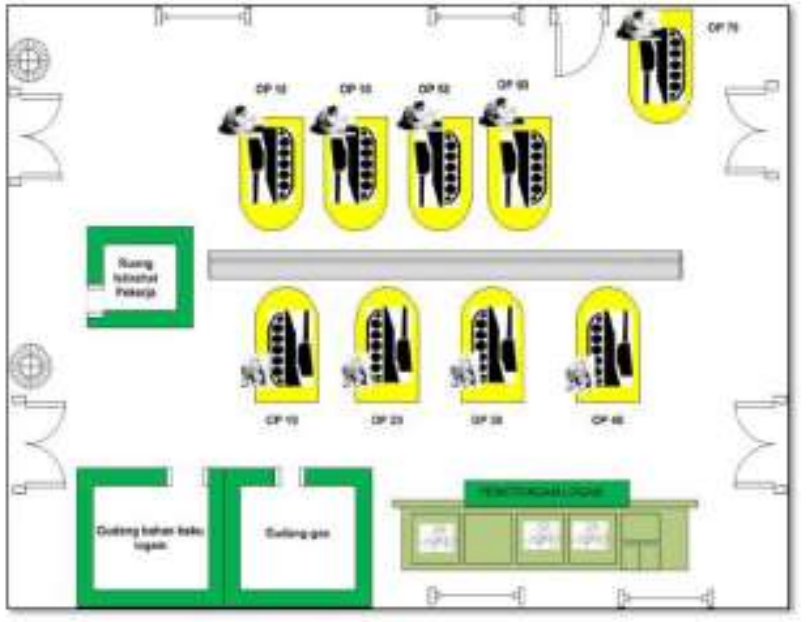

Gambar 1. Denah Lokasi Penelitian.

\subsection{Pengambilan Sampel}

Jumlah sampel udara pernapasan sebanyak 28 sampel yang berasal dari 19 orang kelompok pengelas dan nonpengelas (administrasi). Pengambilan sampel udara menggunakan Personal Sampling Pump Gilian HFS-513A yang telah terkalibrasi di daerah pernapasan pekerja. Filter Mixed Cellulose Ester (MCE) berdiameter $25 \mathrm{~mm}$ dan ukuran pori $0.8 \mu \mathrm{m}$ diletakan pada cassette holder dengan SKC aluminium cyclone 225-01-01/02 untuk menampung fume pengelasan. Debit atau laju alir udara yang digunakan maksimum $2 \mathrm{~L} /$ menit sesuai dengan yang disarankan OSHA. Pengambilan sampel udara pernapasan dilakukan ketika pengelasan berlangsung dengan rentang waktu yang berbeda-beda untuk setiap pengelas karena tergantung dari pesanan.

\subsection{Analisis}

Filter MCE dianalisis dengan metode gravimetri untuk mengetahui konsentrasi massa partikulat yang terhisap. Penimbangan awal diperlukan pada filter kosong atau sebelum digunakan yang selanjutnya digunakan untuk mengetahui selisih berat filter setelah dan sebelum sampling. Untuk mengetahui konsentrasi massa partikulat dapat digunakan perhitungan sebagai berikut.

$$
C s=\frac{M s}{V}
$$

Dimana Cs merupakan konsentrasi massa partikulat $\left(\mu \mathrm{g} / \mathrm{m}^{3}\right)$, Ms adalah selisih filter kosong dan setelah sampling $(\mu \mathrm{g})$, dan $\mathrm{V}$ didefinisikan volum $\left(\mathrm{m}^{3}\right)$ yang didapatkan dari hasil kali debit personal sampling pump dengan durasi pengambilan sampel.

Penentuan indeks bahaya (Hazard Index) dilakukan dengan menghitung nilai Hazard Quotient (HQ) yang merupakan hasil bagi dosis rata-rata per hari (Average Daily
Dose/ADD) dengan nilai ambang batas (Reference Dose/RfD). Selanjutnya nilai HQ yang didapat digunakan untuk menghitung HI (Soemirat, 2005).

$$
\begin{gathered}
H I=\sum_{i=1}^{n} H Q \\
H Q=\frac{A D D}{R f D}
\end{gathered}
$$

Persamaan (4) digunakan untuk mencari besar dosis per hari yang diterima oleh pekerja, baik pengelas dan nonpengelas.

$A D D\left(\frac{m g}{k g \times h a r i}\right)=\frac{C A \times I R \times E T \times E F \times E D}{B W \times A T}$

Dengan keterangan sebagai berikut.

$\mathrm{CA}=$ konsentrasi kontaminan di udara $\left(\mathrm{mg} / \mathrm{m}^{3}\right)$

IR = rata-rata inhalasi $\left(\mathrm{m}^{3} / \mathrm{jam}\right)$

$\mathrm{ET}=$ waktu pajanan $(\mathrm{jam} / \mathrm{hari})$

$\mathrm{EF}=$ frekuensi pajanan (hari/tahun)

$\mathrm{ED}=$ durasi pajanan (tahun)

$\mathrm{BW}=$ berat badan $(\mathrm{kg})$

$\mathrm{AT}=$ waktu rata-rata $(\mathrm{ED} \times 365$ hari/tahun $)$

\section{Hasil dan Pembahasan}

\subsection{Konsentrasi Partikulat Terespirasi}

Hasil perhitungan dengan metode gravimetri menunjukan bahwa rata-rata konsentrasi partikulat terespirasi di unit produksi dan administrasi menunjukan nilai 7.913,94 $\mu \mathrm{g} / \mathrm{m}^{3}$ pada pengelas dan $219,91 \mu \mathrm{g} / \mathrm{m}^{3}$ di pekerja non-pengelas bagian administrasi (Gambar 2). Gambar 3 juga menegaskan bahwa paparan partikulat terespirasi yang diterima antara pengelas dan non-pengelas berbeda jauh. Perbedaan ini dapat disebabkan karena kondisi masing-masing lingkungan kerja di mana pada Departemen Produksi 1 terdapat aktivitas yang tinggi sehingga dihasilkan emisi yang tinggi pula. Hal ini berbeda pada administrasi di mana pekerja tidak mendapat pengaruh yang begitu besar dari lingkungan sekitarnya.

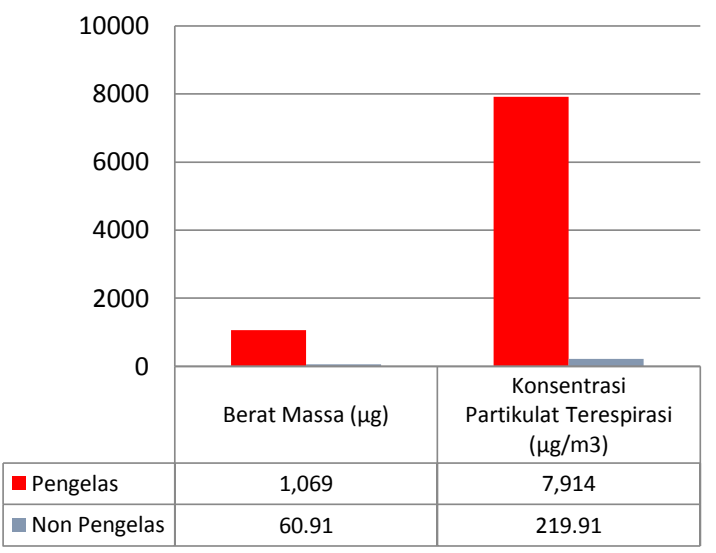

Gambar 2. Rata-rata berat massa dan konsentrasi total partikulat terespirasi. 
Jika dibandingkan dengan baku mutu konsentrasi partikulat terespirasi yang ditetapkan, TWA PEL fume pengelasan $\left(\mu \mathrm{g} / \mathrm{m}^{3}\right)$ ACGIH, yaitu $5000 \mu \mathrm{g} / \mathrm{m}^{3}$, rata-rata konsentrasi partikulat terespirasi pada kelompok pengelas telah melewati baku mutu. Peraturan Pemerintah Indonesia juga memberikan hasil yang tidak jauh berbeda di mana Surat Edaran Menteri Tenaga Kerja SE.01/MEN/1997 tentang Nilai Ambang Batas (NAB) faktor kimia di lingkungan kerja, yang menyatakan bahwa baku mutu kadar partikulat terespirasi tidak boleh melebihi $3.000 \mu \mathrm{g} / \mathrm{m}^{3}$. Tingginya nilai ini mungkin disebabkan ada kegiatan yang berkontribusi selain pengelasan. Pada saat pengambilan sampel, sangat dimungkinkan ada pekerja yang tidak sedang mengelas, misalnya saja sedang melakukan gerinda (grinding). Pengamatan di lapangan menunjukkan bahwa tidak menutup kemungkinan pengelas berdekatan dengan pekerja lain yang sedang melakukan proses gerinda. Gerinda biasanya dilakukan pada saat sebelum pengelasan dilakukan untuk membuat jalur mengelas.

Hasil ini sedikit berbeda ketika dibandingkan dengan Keputusan Menteri Kesehatan No.1405/MenKes/SK/XI/2002 bahwa baku mutu debu total di dalam ruangan kerja pada industri selama 8 jam, yaitu $10.000 \mu \mathrm{g} / \mathrm{m}^{3}$. Nilai rata-rata konsentrasi total partikulat pada kelompok pengelas masih di bawah baku mutu tersebut $\left(7.913,94 \mu \mathrm{g} / \mathrm{m}^{3}\right)$. Satu hal yang menjadi perhatian adalah durasi pengambilan sampel bervariasi dan tidak sampai 8 jam kerja karena disesuaikan dengan banyaknya pesanan sehingga ada kemungkinan nilai rata-rata konsentrasi total partikulat terespirasi kelompok pengelas bertambah tinggi bahkan melewati baku mutu yang ditetapkan.

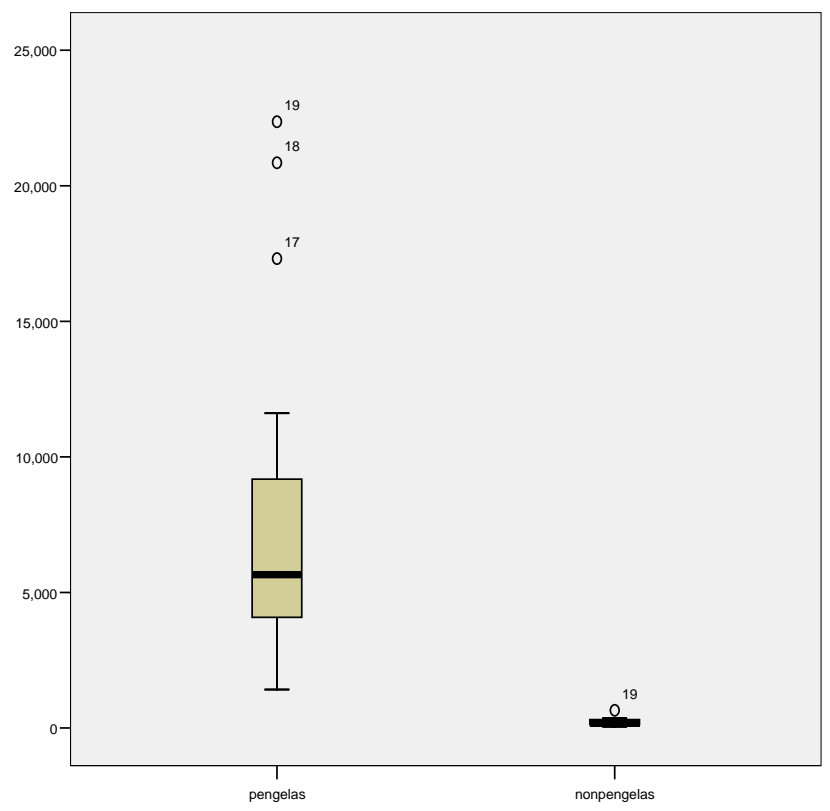

Gambar 3. Boxplot Konsentrasi Partikulat Terespirasi Pengelas dan Non-Pengelas

Pada kelompok non-pengelas, terhitung rata-rata konsentrasi total partikulat sebesar 219,91 $\mu \mathrm{g} / \mathrm{m}^{3}$. Jika dibandingkan dengan Keputusan Menteri Kesehatan No.1405/MenKes/SK/XI/2002 bahwa baku mutu debu total di dalam ruangan kerja perkantoran selama 8 jam, yaitu 150 $\mu \mathrm{g} / \mathrm{m}^{3}$, nilai tersebut telah melewati baku mutu yang telah ditetapkan. Ada beberapa hal yang diperkirakan mempengaruhi nilai tersebut, misalnya perawatan (housekeeping) ruangan yang kurang maksimal, sistem ventilasi yang kurang baik, dan perilaku pekerja. Perilaku pekerja yang dimaksud adalah pekerja dengan kebiasaan merokok bebas merokok di dalam ruangan kerja. Kebiasaan yang tidak baik ini diperkirakan dapat mempengaruhi ratarata konsentrasi total partikulat terespirasi.

Pramudyastuti (2009) melakukan penelitian pada pengelas yang menggunakan tipe las Manual Metal Arc Welding (MMAW) mengatakan bahwa rata-rata konsentrasi partikulat terespirasi pengelas sebesar $1.625,3 \mu \mathrm{g} / \mathrm{m}^{3}$. Nilai tersebut masih berada di bawah nilai paparan yang diterima pengelas PT. X. Ada beberapa alasan yang diperkirakan mempengaruhi kondisi itu. Pertama, tipe mesin pengelasan yang berbeda di mana penelitian ini dilakukan pada tipe mesin Gas Metal Arc Welding (GMAW). Kedua, kondisi lingkungan kerja yang berbeda di mana kegiatan pengelasan PT. X dilakukan di dalam ruangan dan pengelasan ada yang dilakukan di dalam rangka kendaraan. Ketiga, sistem ventilasi yang kurang memadai.

Besaran paparan partikulat terespirasi yang diterima setiap pekerja berbeda-beda. Hasil yang didapatkan menunjukan rentang konsentrasi partikulat terespirasi pekerja non-pengelas berkisar antara 52,26-652,65 $\mu \mathrm{g} / \mathrm{m}^{3}$ (Gambar 3). Nilai terendah yang didapat berada di bawah baku mutu yang ditetapkan Keputusan Menteri Kesehatan No.1405/MenKes/SK/XI/2002. Pada saat pengambilan sampel, tidak semua pekerja berada di dalam ruangan. Terdapat beberapa pekerja yang melakukan tugasnya di lapangan atau cuti. Selain itu, aktivitas pekerja hanya melaksanakan tugas di meja masing-masing. Nilai maksimum konsentrasi partikulat terespirasi adalah 652,65 $\mu \mathrm{g} / \mathrm{m}^{3}$. Tingginya nilai ini diperkirakan karena banyak pekerja yang melakukan aktivitas lain, misalnya merokok. Sebagai informasi tambahan, hampir pekerja non-pengelas (administrasi) yang mempunyai kebiasaan merokok dengan bebas merokok di dalam ruangan. Hal ini diperkirakan mempengaruhi hasil yang didapat dalam penelitian ini.

Pada kelompok pengelas, nilai minimum konsentrasi partikulat terespirasi 1.418,26 (Gambar 3). Pada kondisi ini, pengelas bekerja di luar rangka panser dan di sekitar pengelas teramati tidak ada aktivitas lain yang diperkirakan mempengaruhi konsentrasi partikulat terespirasi. Untuk nilai konsentrasi partikulat terespirasi tertinggi, yakni 22.363,36 $\mu \mathrm{g} / \mathrm{m}^{3}$. Tingginya nilai tersebut salah satunya dapat disebabkan lokasi pengelasan berada di dalam rangka panser. Pengelasan di dalam rangka panser biasanya dibantu blower. Hanya saja, adanya blower dirasakan kurang efektif karena konsentrasi partikulat terespirasi masih tinggi. Sebenarnya pengelas juga dibantu Local Exhaust Ventilation (LEV), tetapi pada kenyataannya LEV ini kurang difungsikan dengan baik dan benar. Terkadang hanya sebagai pelengkap. Faktor lain yang diperkirakan berpengaruh, yakni adanya aktivitas lain seperti grinding atau gerinda. Proses gerinda juga menghasilkan debu yang mampu mempengaruhi nilai dari konsentrasi pertikulat terespirasi. Gerinda terkadang dilakukan pekerja sebelum pengelasan dilakukan. Penggunaaan lainnya ketika hasil pengelasan dirasakan kurang maksimal dan pengelas menghilangkan pengelasan terdahulu menggunakan gerinda. 
Berdasarkan Gambar 3., terdapat 3 konsentrasi dengan nilai ekstrem pada pengelas dan 1 pada non-pengelas. Konsentrasi partikulat terespirasi ini terjadi diperkirakan adanya pengaruh dari lingkungan sekitar. Pada kelompok pengelas, tingginya nilai konsentrasi tersebut diperkirakan karena adanya aktivitas lain yang mempengaruhi, misalnya gerinda. Aktivitas ini juga menghasilkan partikulat yang dapat mempengaruhi nilai konsentrasi partikulat terespirasi. Aktivitas yang diperkirakan mempengaruhi konsentrasi partikulat terespirasi pada kelompok non-pengelas salah satunya asap rokok. Pekerja lain yang berada di bagian administrasi (non-pengelas) bebas merokok.

Tabel 1 menunjukkan perbandingan nilai kosentrasi partikulat terespirasi pada beberapa penelitian. Dapat dilihat bahwa konsentrasi partikulat terespirasi pada penelitian ini lebih tinggi dibandingkan penelitian yang dipaparkan. Kondisi lingkungan kerja yang berbeda diperkirakan menjadi peyebabnya. Di PT. X, semua aktivitas dilakukan di workshop yang tertutup dan hanya dilengkapi ventilasi umum. Jenis ventilasi ini diperkirakan kurang memadai untuk mengurangi paparan partikulat terhadap pekerja. Aktivitas pengelasan dibantu oleh LEV tapi keberadaannya kurang dimanfaatkan.

Tabel 1

Hasil penelitian mengenai partikulat terespirasi di beberapa wilayah.

\begin{tabular}{|c|c|c|}
\hline Peneliti & Lokasi & Hasil \\
\hline $\begin{array}{l}\text { Lilis Agustanti } \\
(\text { 2003) }\end{array}$ & $\begin{array}{l}\text { Pengolahan aki } \\
\text { bekas, Semarang }\end{array}$ & $\begin{array}{l}\text { Rata-rata } \\
\text { konsentrasi } \\
\text { partikulat } \\
\text { terespirasi } 1,11 \\
\mathrm{mg} / \mathrm{m}^{3}\end{array}$ \\
\hline $\begin{array}{l}\text { Noneng Zannaria } \\
\text { (2008) }\end{array}$ & $\begin{array}{l}\text { Area industri di } \\
\text { Cisaranten, } \\
\text { Bandung }\end{array}$ & $\begin{array}{l}\text { Rata-rata } \\
\text { konsentrasi } \\
\text { partikulat } \\
\text { terespirasi } \\
\text { masyarakat } 0,072 \\
\mathrm{mg} / \mathrm{m}^{3}\end{array}$ \\
\hline $\begin{array}{l}\text { Kuverega dan } \\
\text { Taru (2008) }\end{array}$ & $\begin{array}{l}\text { Area sekitar } \\
\text { industri, } \\
\text { Zimbabwe }\end{array}$ & $\begin{array}{l}\text { Konsentrasi } \\
\text { partikulat } \\
\text { terespirasi } \\
\text { masyarakat } 40,55 \\
\mathrm{mg} / \mathrm{m}^{3}\end{array}$ \\
\hline $\begin{array}{l}\text { Pramudyastuti, } \\
\text { D.Y. (2009) }\end{array}$ & $\begin{array}{l}\text { Daerah UKM } \\
\text { pengelasan, } \\
\text { Bandung }\end{array}$ & $\begin{array}{l}\text { Rentang } \\
\text { konsentrasi } \\
\text { partikulat } \\
\text { terespirasi } 315,6- \\
3.735,93 \mu \mathrm{g} / \mathrm{m}^{3}\end{array}$ \\
\hline $\begin{array}{l}\text { Tiwari et al. } \\
\text { (2010) }\end{array}$ & $\begin{array}{l}\text { Daerah masyarakat } \\
\text { sekitar industri, } \\
\text { India }\end{array}$ & $\begin{array}{l}\text { Rata-rata } \\
\text { konsentrasi } \\
\text { partikulat } \\
\text { terespirasi tahunan } \\
97 \mu \mathrm{g} / \mathrm{m}^{3}\end{array}$ \\
\hline $\begin{array}{l}\text { Essa, Wiedy Y. } \\
\text { (2011) }\end{array}$ & $\begin{array}{l}\text { Daerah sekitar } \\
\text { industri aki bekas, } \\
\text { Tangerang }\end{array}$ & $\begin{array}{l}\text { Rata-rata } \\
\text { konsentrasi } \\
\text { partikulat } \\
\text { terespirasi } 0,168 \\
\mathrm{mg} / \mathrm{m}^{3}\end{array}$ \\
\hline
\end{tabular}

\subsection{Indeks Bahaya}

Gambar 4 menunjukkan indeks bahaya paparan partikulat terespirasi terhadap pekerja di kelompok masing-masing. Dapat dilihat bahwa nilai Indeks Bahaya kelompok pengelas
$(9,45)$ lebih besar dari kelompok non-pengelas $(0,51)$. Gratt (1996) dalam Wibawa (2008) mengatakan bahwa nilai HI lebih dari satu menggambarkan bahwa kegiatan pengelasan berbahaya terhadap kesehatan paru-paru pekerja. Bahaya tersebut berasal dari paparan fume pengelasan dan aktivitas lainnya seperti gerinda. Meskipun nilai HI pekerja nonpengelas tidak lebih dari 1 , perlu diwaspadai adanya kemungkinan bahaya dari partikulat terespirasi.

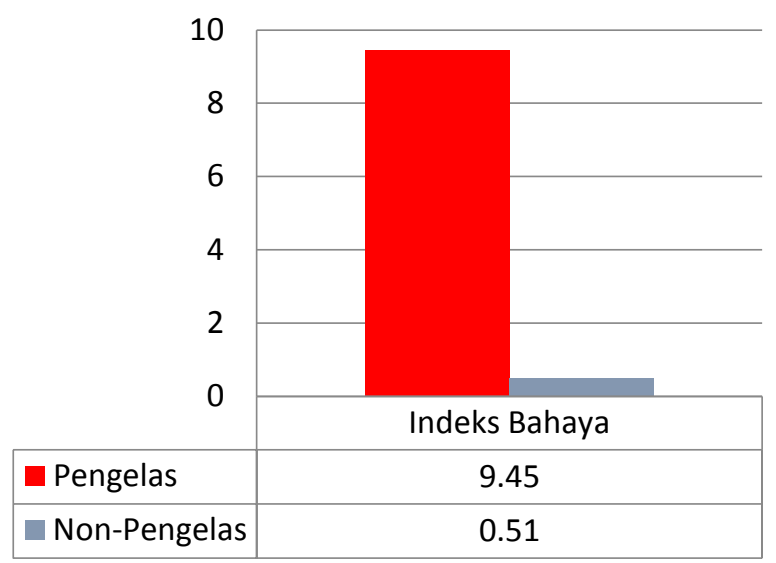

Gambar 4. Indeks Bahaya.

\section{Simpulan}

Pengelas pada Departemen Produksi 1 PT. X terpapar fume pengelasan yang diperkirakan dapat membahayakan kesehatan. Rata-rata konsentrasi partikulat terespirasi yang tinggi $7.913,94 \mu \mathrm{g} / \mathrm{m}^{3}$ memberikan pemahaman bahwa paparan fume pengelasan tinggi dan berisiko terhadap kesehatan pengelas. Untuk itu, diperlukan analisis lebih mendalam mengenai dampak kesehatan fume pengelasan terhadap kesehatan pengelas. Selain itu, hasil peneltian ini juga dapat digunakan untuk menentukan langkah-langkah mengurangi paparan fume pengelasan kepada pekerja.

\section{Ucapan Terima Kasih}

Penulis menyampaikan terima kasih kepada Dr. Muhayatun Santoso atas kesempatan yang diberikan untuk menganalisis data di laboratorium Pusat Teknologi Nuklir Bahan dan Radiometri Badan Tenaga Nuklir Nasional, Bandung.

\section{Daftar Pustaka}

Ashby, H.S., 2002. Welding Fume in the Workplace: Preventing Potential Health Problems Through Proactive Controls. Proffesional Safety. Page 55-60.

Chae, Hyunbyung; Cheolhee K.; Jeonghan K. and Sehun R., 2006. Fume Generation Behaviors in Short Circuit Mode during Gas Metal Arc Welding and Flux Cored Arc Welding. Materials Transactions, Vol. 47, No. 7 (2006) pp. 1859 to 1863

IARC, 1990. IARC Monographs On The Evaluation Of Carcinogenic Risks To Humans: Chromium, Nickel, And Welding. Volume 49, Lyon: France.

Kuvarege, A.T. dan Taru, P., 2008. Ambiental Dust Speciation and Metal Content Variation In TSP, $\mathrm{PM}_{10}$, and $\mathrm{PM}_{2.5}$ In Urban Atmospheric Air Of Harare (Zimbabwe). Eviron Monit Asess. Vol. 144, page 1-14

Pramudyastuti, Diana Yuniarti. 2009. Karakterisasi dan Identifikasi Bahaya Uap Logam Terespirasi Pada Proses Pengelasan (Welding Fume). Tesis Magister Teknik Lingkungan, Institut Teknologi Bandung. 
Soemirat, Juli, 2005. Epidemiologi Lingkungan. Gadjah Mada University Press, Yogyakarta.

Tiwari, Suresh; Ratul K.S.; Deewan S.B; Tarannum B.; Sachchidanand S.; Sudhamayee B.; Manoj K.S.; Chate, D.M.; Padmanabhamurty B. 2010. Black Carbon And Chemical Characteristics Of $\mathrm{PM}_{10}$ And $\mathrm{PM}_{2.5}$ At An Urban Site Of North India. J Atmos Chem. Vol. 62, page 193-209.

Wibawa, K. 2008. Analisis Risiko Kesehatan Pajanan Debu Terhadap Nilai $\mathrm{FEV}_{1.0}$ Pekerja di Lingkungan Kerja PT. X. Tesis Program Magister Teknik Lingkungan, Institut Teknologi Bandung. 